\title{
Intestinal Calcium-Binding Protein in the Developing Rat Duodenum
}

\author{
WALLACE A. GLEASON, JR. ${ }^{(3 ;)}$ AND GARY L. LANKFORD \\ Division of Gastroenterology and Nutrition, Department of Pediatrics, The University of Texas Health Science Center, \\ at San Antonio, Texas, USA
}

\begin{abstract}
Summary
An immunoassay for rat intestinal calcium-binding protein (CaBP) employing antibody raised in chickens using purified rat intestinal $\mathrm{CaBP}$ has been used to measure immunoreactive $\mathrm{CaBP}$ in the duodenum of suckling and weanling rats. A 5-fold increase in immunoreactivity, associated with a $2 \frac{1}{1} 2$-fold increase in calciumbinding activity occurred at weaning, a period during which duodenal mucosal mass increased 2 -fold and supernatant protein concentration increased $1 \frac{1}{2}$-fold.
\end{abstract}

\section{Speculation}

The ontogeny of calcium-binding protein in the duodenum of young rats parallels the maturation of cholecalciferol hydroxylases and represents maturation of the intestine as an end organ responsive to the vitamin $D$ endocrine system.

The exact mechanism by which vitamin D stimulates calcium transport remains unclear (10). A major theory holds that 1,25dihydroxycholecalciferol, the vitamin $\mathrm{D}$ metabolite most active in stimulating active calcium transport, acts analogously to other steroid hormones (19). Following this analogy, 1,25-dihydroxycholecalciferol is bound by specific receptors in the cytoplasm of the intestinal epithelial cell (6). The receptor-hormone complex subsequently binds nuclear chromatin (5), resulting in the synthesis of messenger RNA, $(29,33)$ and ultimately, specific proteins responsible for the effect of the hormone on the end organ cell.

The protein most convincingly demonstrated as a result of the interaction between 1,25-dihydroxycholecalciferol and the intestinal epithelial cell is the vitamin D-dependent intestinal calciumbinding protein ( $\mathrm{CaBP}$ ) (31). A role for the $\mathrm{CaBP}$ in vitamin $\mathrm{D}$ dependent active intestinal calcium transport has not yet been clearly defined, but its identification as a specific product of the interaction of the vitamin $D$ endocrine system and the intestinal mucosa (12) makes it useful as a molecular marker of the vitamin D-dependent intestinal calcium transport mechanism.

Functional maturation of the intestinal mucosa in the suckling animal is characterized by enhancement of mucosal enzyme activities and active transport systems (20), and localization of these digestive and transport functions to the site of their maximal activity in the mature intestine (2). Calcium absorption occurs throughout the small intestine and colon of the suckling rat (2) and is not vitamin D-dependent (11). This widespread absorption of calcium decreases with maturation, $(2,32)$ and is replaced at weaning by active (1), vitamin D-dependent (11) calcium transport localized to the duodenum (2), the site of its maximal activity in the intestine of the adult animal $(28,30)$.

DeLorme, et al. (9) and Bruns, et al. (7) have shown a corresponding increase in intestinal CaBP, measured by immunochemical techniques, between days 17 and 22 after birth.

The purpose of this investigation was to further define the ontogeny of $\mathrm{CaBP}$ in the developing duodenum, relating it to the hypertrophy and functional maturation that characterize the in- testine at weaning. We therefore developed an immunoassay for the purified rat intestinal $\mathrm{CaBP}$ (15) and, using this assay, measured immunoreactive $\mathrm{CaBP}$ in homogenates of duodenal mucosa from suckling and weanling animals, comparing such changes to changes in mucosal weight, supernatant protein concentration and calcium-binding activity.

\section{MATERIALS AND METHODS}

One and one-half $\mathrm{mg}$ of rat intestinal $\mathrm{CaBP}$ purified to homogeneity in our laboratory by heat treatment, gel filtration chromatography, and ion exchange chromatography (15), were dispersed in complete Freund's adjuvant and injected subcutaneously into the footpads of each of two young adult Leghorn hens (Al Blum Rabbitry, San Antonio). Each animal received a booster dose of $0.5 \mathrm{mg}$ intramuscularly $4 \mathrm{wk}$ later. Six wk after the original injection, $10 \mathrm{ml}$ of blood was obtained from the wing vein of each animal. Serum was separated and stored at $-20^{\circ} \mathrm{C}$ for further testing.

The chicken antiserum was tested for antibody by Ouchterlony double immunodiffusion (27) in $1 \%$ agarose containing $8 \% \mathrm{NaCl}$ (Fig. 1). Ten $\mu$ liters of the chicken antiserum were pipetted into the center well. The outer wells contained aliquots from preparations of the rat intestinal $\mathrm{CaBP}$ of varying degrees of purity: the crude, heated supernatant of the mucosal homogenate (well A), the pooled peak of calcium-binding activity eluted from a gel filtration column (well B) and the purified CaBP (well C).

Immunoelectrophoresis was carried out to further establish the specificity of the chicken anti-rat CaBP (Fig. 2). Thirty $\mu \mathrm{g}$ of protein from the heated supernatant of the rat intestinal mucosal homogenate and $10 \mu \mathrm{g}$ of the ion exchange purified CaBP were electrophoresed in a polyacrylamide disc gel electrophoresis system using $7 \%$ polyacrylamide at a running $\mathrm{pH}$ of 8.9 in the presence of $0.3 \mathrm{mM} \mathrm{CaCl}_{2}(8)$. After electrophoresis, the gels were placed on a film of $1 \%$ agarose in $8 \% \mathrm{NaCl}$. A trough was cut in the agrose, parallel to the gel, and $50 \mu$ liters of the chicken antiserum was pipetted into the trough.

Quantitative measurement of immunoreactive $\mathrm{CaBP}$ was carried out using radial immunodiffusion as described by Mancini, et al. (24). Twenty $\mu$ liters of the chicken antiserum was added to each $\mathrm{ml}$ of $1 \%$ agarose in $8 \% \mathrm{NaCl}$ and the mixture was poured onto Gel Bond plates (FMC Corp., Rockland, ME). After solidification of the agarose, wells were cut and 2.5-10 $\mu$ liters of a standard solution of the purified rat intestinal $\mathrm{CaBP}$ was pipetted into each well.

The agarose plates were incubated at room temperature for 48 $h$, then washed twice in distilled deionized water, dried and stained by immersion in $0.1 \%$ thiazine red in $0.1 \%$ acetic acid for all of the above immunochemical techniques. After washing in $50 \%$ methanol: $10 \%$ acetic acid, they were again dried. For calculation of immunoreactive CaBP, the diameter of the zone of immunoprecipitation in the radial immunodiffusion system was measured. The area of the zone of immunoprecipitate was calculated and plotted against the log of the amount of $\mathrm{CaBP}$ added to the well. A linear relationship existed between $0.5-25 \mu \mathrm{g}$ of $\mathrm{CaBP}$. 


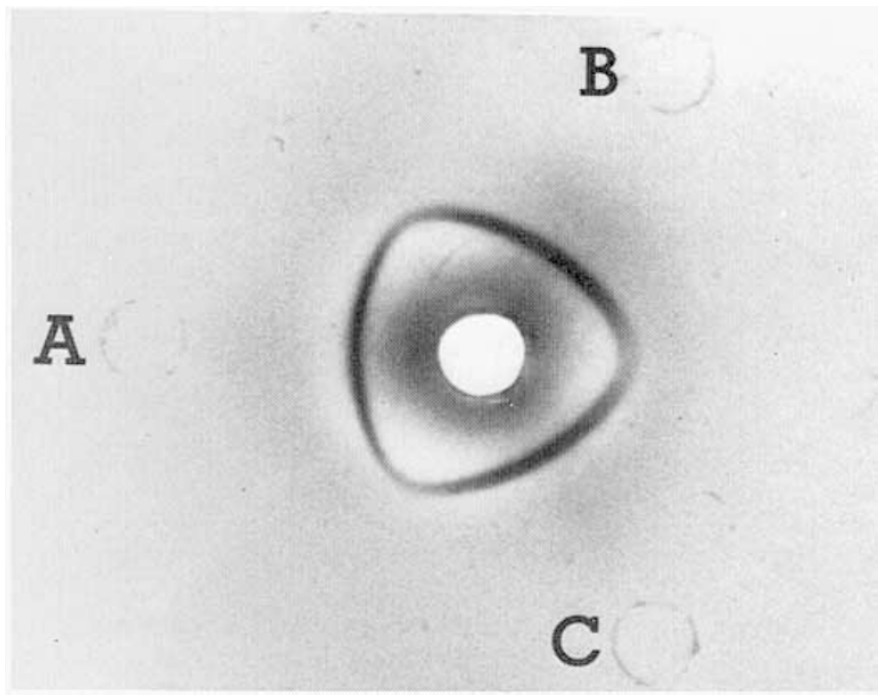

Fig. 1. Double immunodiffusion of the chicken anti-rat calcium-binding protein $(\mathrm{CaBP})$. Ten $\mu$ liters of the chicken anti-rat $\mathrm{CaBP}$ was placed in the center well. Well $\mathrm{A}$ contains $22 \mu \mathrm{g}$ of protein from the crude, heattreated intestinal mucosal supernatant. Well B contains $4 \mu \mathrm{g}$ of protein from the pooled fractions within the gel filtration peak of calcium-binding activity. Well $\mathrm{C}$ contains $0.6 \mu \mathrm{g}$ of the purified rat intestinal $\mathrm{CaBP}$.

Female Sprague-Dawley rats were mated, housed in nesting boxes, and allowed ad libitum access to chow containing $1.2 \%$ calcium, 0.99\% phosphorus and distilled, deionized water. Births of pups were noted, and the pups were weighed at weekly intervals. The pups were suckled as their only source of nourishment but had free access to water.

The pups were sacrificed at from 1-7 weeks of age. Duodenal segments, anatomically defined as beginning at the pylorus and ending at the duodenal ligament corresponding to the ligament of Treitz in man, were removed, rinsed in ice cold $0.9 \% \mathrm{NaCl}$, blotted, and weighed. After weighing, the duodenal segments were homogenized in 3 volumes of $0.0137 \mathrm{M}$ Tris- $\mathrm{HCl}, \mathrm{pH} 7.4$, with $0.12 \mathrm{M} \mathrm{NaCl}, 0.003 \mathrm{M} \mathrm{KCl}$. The homogenates were heated at $65^{\circ} \mathrm{C}$ for $5 \mathrm{~min}$, incubated for $5 \mathrm{~min}$ at $4^{\circ} \mathrm{C}$, and centrifuged at $30,000 \times g$ for $30 \mathrm{~min}$. The resulting heat-treated supernatant was assayed for calcium-binding activity using a modification of the Chelex-100 competitive radiocalcium-binding assay (14). For each determination duodenal segments were pooled from four 1-weekold, four 2-week-old, and two 3-week-old pups.

Immunoreactive $\mathrm{CaBP}$ was quantitated in the heated supernatants from neonatal rat duodenum by radial immunodiffusion. Because the relationship between the area of the immunoprecipitate and the log of the CaBP concentration was linear between 0.5-25 $\mu \mathrm{g} \mathrm{CaBP}$, samples were diluted and assayed in this range. Supernatant protein was determined using the method of Lowry, et al. (22). Data was analyzed using one way analysis of variance (4).

\section{RESULTS}

The Ouchterlony double diffusion experiment revealed a single line of immunoprecipitate between the center well, containing the chicken anti-rat $\mathrm{CaBP}$ and the outer wells containing the crude, heat-treated rat intestinal mucosal supernatant, the partially purified preparation of the $\mathrm{CaBP}$, and the purified $\mathrm{CaBP}$ (Fig. 1). This line formed a line of identity, with no spurs, between the outer wells. Immunoelectrophoresis revealed a single arc of immunoprecipitate, corresponding to the protein band with the characteristic mobility of the rat intestinal $\mathrm{CaBP}$ in all three preparations (Fig. 2)

The sensitivity of the chicken anti-rat $\mathrm{CaBP}$, as determined by testing various concentrations of the purified CaBP by Ouchterlony double diffusion, was in the range of $0.1 \mu \mathrm{g}$.
The pattern of gain in total body weight and weight of the duodenal segments is shown in Figure 3. Intestinal mucosal growth, as evidenced by increasing duodenal segment weight and supernatant protein concentration, showed the characteristic increase in rate of mucosal growth between wk 2 and 3, just before weaning (26). Soluble protein content of the mucosal supernatant increased $1 / 2$-fold between wk two and three and remained constant thereafter.

Small amounts of calcium-binding activity were seen in the heated intestinal mucosal supernatants from suckling animals (Fig. 4). These values increased $21 / 2$-fold in the wk before weaning. High levels of calcium-binding activity persisted to $5 \mathrm{wk}$ of age, at which time they decreased to $1 \frac{1 / 2}{2}$ times that seen in the suckling

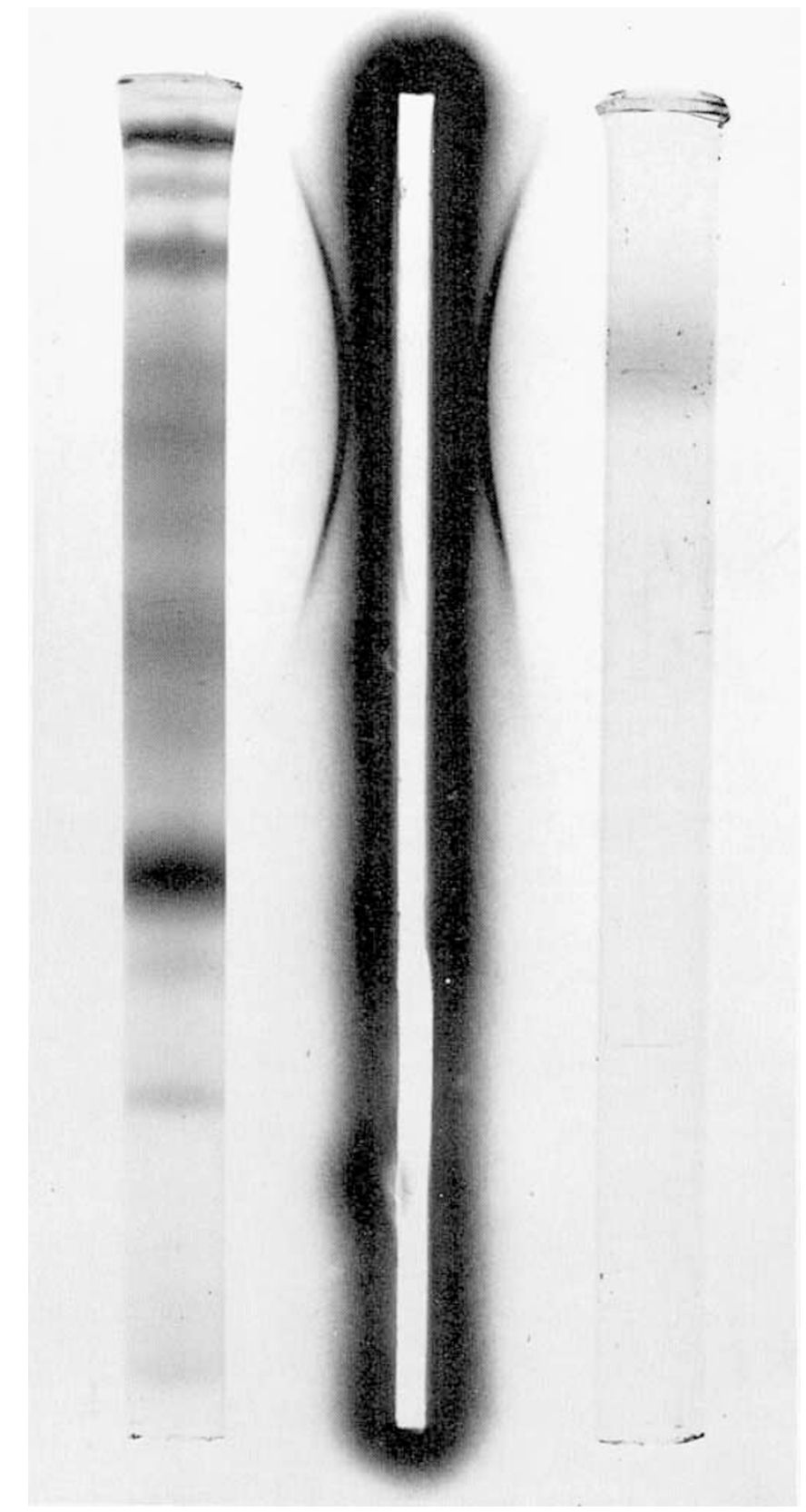

Fig. 2. Immunoelectrophoretic analysis of the chicken anti-rat calciumbinding protein $(\mathrm{CaBP})$. The trough in the center contains $50 \mu$ liters of the chicken anti-rat $\mathrm{CaBP}$. The gel on the left shows the electrophoretic pattern of $30 \mu \mathrm{g}$ of protein from the heated supernatant from the rat intestinal mucosal homogenate. The gel on the right, $10 \mu \mathrm{g}$ of purified rat intestinal $\mathrm{CaBP}$. The arc of immunoreactivity corresponds to the electrophoretic position of the $\mathrm{CaBP}$. 


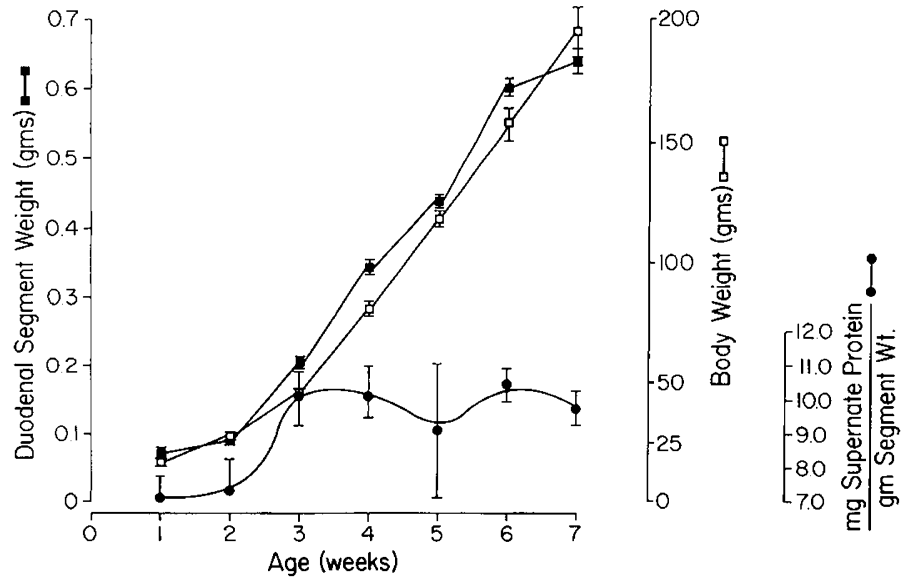

Fig. 3. Pattern of gain in body weight, duodenal segment weight and protein content of the mucosal supernatant during suckling and weanling periods.

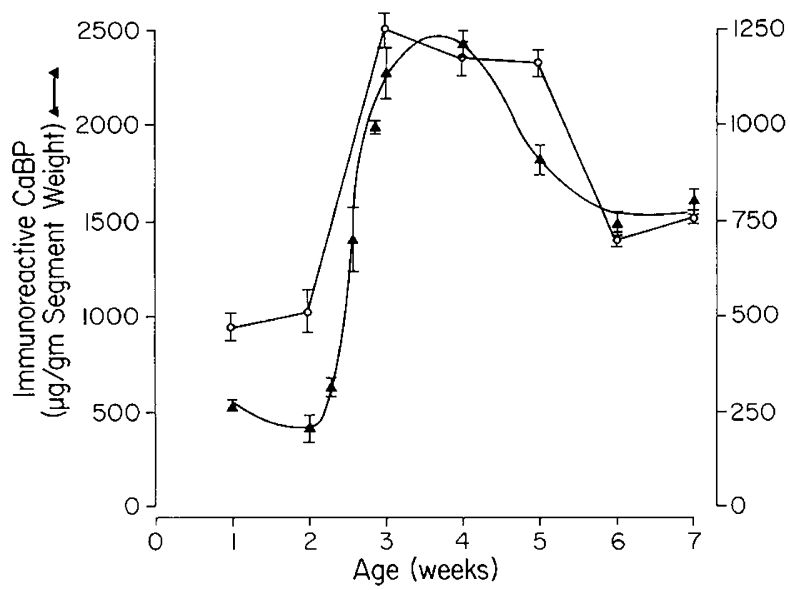

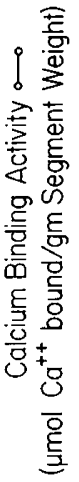

Fig. 4. Calcium-binding activity and calcium-binding protein immunoreactivity in heat-treated supernatants of duodenum during the suckling and weanling periods.

intestine. Changes in immunoreactive CaBP paralleled the changes in calcium-binding activity but were more dramatic. The peak of immunoreactive $\mathrm{CaBP}$ concentration occurred at weaning and resulted in a 5 -fold increase over immunoreactive $\mathrm{CaBP}$ in the suckling intestine. A similar decrease in CaBP concentration was seen after weaning, beginning at $4 \mathrm{wk}$ and resulting in a net 3 -fold increase in $\mathrm{CaBP}$ concentration between the suckling period and the second month of life.

Because of the marked change in calcium-binding activity and immunoreactive $\mathrm{CaBP}$ concentrations between wk 2 and 3 , the change was more closely monitored by sampling duodenal segments from suckling animals at days 16, 18, and 20 of age. The additional points indicate that the increase in CaBP begins promptly at 15 to 16 days of age, and results in a rather abrupt increase in $\mathrm{CaBP}$, tripling in 4 days and peaking within less than a wk.

\section{DISCUSSION}

This paper reports the production of a specific chicken anti-rat $\mathrm{CaBP}$ and its use in immunochemical quantitation of $\mathrm{CaBP}$ in the developing duodenum. Repeated attempts at producing an antibody by immunizing rabbits with up to $3 \mathrm{mg}$ of the purified rat intestinal $\mathrm{CaBP}$ were unsuccessful in our hands. We therefore selected the chicken, because of its phylogenetic distance from the rat, and because of the successful experience of others in producing antibodies using this animal $(3,18)$.
The antibody produced in these studies appears to be highly specific for rat intestinal CaBP. A single line of immunoprecipitate appears when it is tested by immunodiffusion against the crude heat-treated rat intestinal mucosal supernatant, the peak of calcium-binding activity eluted off the gel filtration column, and the purified CaBP (Fig. 1). The line of identity formed indicates that the antibody recognizes an immunologically similar protein in each. Absence of spurs indicates that the antibody recognizes only one protein species in each of the three mucosal supernatants of varying purity. Further study of the antibody's specificity using immunoelectrophoresis (Fig. 2) revealed that the antibody recognizes only one protein species in the crude heat-treated intestinal mucosal supernatant whose electrophoretic mobility matches that of the purified protein (15).

Although our finding of a 5-fold increase in immunoreactive $\mathrm{CaBP}$ occurring between days 14 and 21 in the suckling rat intestine confirms similar observations by DeLorme, et al. (9) and Bruns, et al. (7), subtle but important differences should be pointed out.

The antiserum used in our studies is clearly different from that used by DeLorme, et al. in that the protein used to generate it was purified to homogeneity (15), and the specificity of the antigen for the $\mathrm{CaBP}$ is indicated by the immunodiffusion and immunoelectrophoresis experiments here reported. The CaBP antiserum used by DeLorme, et al. was raised to a $\mathrm{CaBP}$ preparation that has two distinct protein bands when studied by polyacrylamide gel electrophoresis (25). The only evidence for the specificity of its recognition of $\mathrm{CaBP}$ is the coelution of $\mathrm{CaBP}$ immunoreactivity with calcium-binding activity from a gel filtration column (25). Additionally, our antibody recognizes porcine intestinal $\mathrm{CaBP}$ (16) whereas theirs reportedly does not (25).

Unlike the study of Bruns et al. (7), duodenal segments sampled in this study were defined anatomically as the segment between the pylorus and the ligament corresponding to the ligament of Treitz in man, rather than by sampling the proximal $20 \mathrm{~cm}$ of small intestine. This allowed standardization of the size of duodenal segments sampled across a broad range of duodenal segment lengths associated with rapid growth in the length of the intestine that occurs during this period (26). Because the duodenum is the site of maximal vitamin $\mathrm{D}$-dependent calcium transport and $\mathrm{CaBP}$ concentration in the mature intestine (28) and this aboral gradient of CaBP has been shown to be present in fetal intestine (9), we anticipated that the changes in CaBP concentration and calciumbinding activity would be most marked in the duodenum.

Finally, the biologic activity of the CaBP-calcium-binding activity was measured and correlated with immunoreactive $\mathrm{CaBP}$ measurements.

The reasons for the sudden and dramatic increase in immunoreactive $\mathrm{CaBP}$ concentration and calcium-binding activity seen before weaning in the suckling rat intestine are unknown. The 5 fold increase in immunoreactive $\mathrm{CaBP}$ concentration and $2 \frac{1}{2} 2$-fold increase in calcium-binding activity (Fig. 4) between wk 2 and 3 occur during a period of rapid growth and maturation of the intestinal mucosa. Supernatant protein concentration increases only $1 \frac{1}{2}$-fold and mucosal weight doubles during the same period. It is unlikely, therefore, that the increase in $\mathrm{CaBP}$ is a nonspecific result of the mucosal hypertrophy and protein synthesis characterizing the preweaning intestine.

Dietary changes, particularly dietary restriction of calcium (14) and phosphorus (13) result in a vitamin D-dependent increase in duodenal $\mathrm{CaBP}$ levels; thus, changes in dietary calcium and phosphorus content during transition from suckling to weanling may be important in initiating the increase in duodenal CaBP seen in these studies. Although the calcium and phosphorus content of rat's milk increases slightly during the first wk of lactation and remains essentially stable thereafter through weaning $(23,21)$, a net decrease in dietary calcium or phosphorus could result from initiation of small amounts of solids in the diet as weaning begins.

Although other lines of evidence indicate that the vitamin D endocrine system is relatively unimportant in the regulation of 
calcium homeostasis in the suckling animal $(11,17)$, the parallel development of pathways of vitamin D metabolism and intestinal responsiveness to 1,25-dihydroxycholecalciferol as manifest by the $\mathrm{CaBP}$ may represent the development of the vitamin $\mathrm{D}$ endocrine system as it exists in the adult animal. Further studies examining intestinal development in general and development of $\mathrm{CaBP}$ in vitamin $\mathrm{D}$-deficient rat pups are necessary to clarify the role of the vitamin $D$ endocrine system in intestinal development in general and development of active calcium transport specifically.

\section{REFERENCES AND NOTES}

1. Adams, P. H., Hill, L. E.. Wain, D., and Taylor, C.: The effects of undernutrition and its relief on intestinal calcium transport in the rat. Calcif. Tis. Res., 16: 293 (1974).

2. Batt, E. R. and Schacter. D.: Developmental patterns of some intestinal transport mechanisms in newborn rats and mice. Am. J. Physiol., 216: 1064 (1969).

3. Benedict, A. A.: Production and purification of chicken immunoglobulins. In: C. A. Williams and M. W. Chase: Methods in Immunology and Immunochemistry. pp. 229-237 (Academic Press. Inc., New York. NY 1967).

4. Browning. J. L. and Kuntz. B. C.: Computational Handbook of Statistics. (Scott Foresman Co., Glenview, IL, 1968).

5. Brumbaugh, P. F. and Haussler, M. R.: $\mid \alpha, 25$-dihydroxycholecalciferol receptors in intestine. I. Association of $1 \alpha, 25$-dihydroxycholecalciferol with intestinal mucosa chromatin. J. Biol. Chem.. 249: 1251 (1974).

6. Brumbaugh, P. F. and Haussler, M. R.: 1 $\alpha .25$-dihydroxycholecalciferol receptors in intestine. II. Temperature-dependent transfer of the hormone to chromatin via a specific cytosol receptor. J. Biol. Chem.. 249: 1258 (1974).

7. Bruns, M. E. H., Bruns, D. E... and Avioli. L. V.: Vitamin D-dependent calciumbinding protein of rat intestine: changes during postnatal development and sensitivity to 1.25-dihydroxycholecalciferol. Endocrinology, 5: 934 (1979).

8. Davis, B. J.: Disc electrophoresis. Ann. N. Y. Acad. Sci.. l2l: 404 (1964).

9. DeLorme, A. C.. Marche, P., and Gorel. J. M.: Vitamin D dependent calciumbinding protein. Changes during gestation, prenatal and postnatal development in rats. J. Devel. Physiol.. I: 181 (1979).

10. Deluca, H. F.: Vitamin D, metabolism and function. In: F. Gross, M. M. Grumbach, A. Lubhart, et al., Eds.: Monographs in Endocrinology. pp. 35-47 (Springer Verlag. New York, NY, 1979).

11. Deluca, H. F.: Some new concepts emanating from a study of the metabolism and function of vitamin D. Nutr. Rev.. 38: 169 (1980).

12. Emtage, J. S., Lawson, D. E. M., and Kodicek, E.: The response of the small intestine to vitamin $\mathrm{D}$. Isolation and properties of chick intestinal polyribosomes. Biochem. J., 140: 239 (1974).

13. Fox, J., Pickard. D. W.. Core. A. D., and Murray, T. M.: Effect of low phosphate diets on intestinal calcium absorption and the concentration of calcium-binding protein in intact and parathyroidectomized pigs. J. Endocr., 78: 379 (1978).

14. Freund, $T$. and Bronner, F.: Regulation of intestinal calcium-binding protein by calcium intake in the rat. Am. J. Physiol., 228: 861 (1975).

15. Gleason, W. A. and Lankford, G. L.: Rat intestinal calcium-binding protein: rapid purification with AG MP-1 ion exchange chromatography. Anal. Biochem. 116: 256 (1981).

16. Gleason. W. A. and Lankford, G. L.: Intestinal calcium-binding protein in the baboon (Papio cynocephalus). Comp. Biochem. Physiol., (in press).
17. Halloran, B. P. and DeLuca, H. F.: Calcium transport in small intestine during early development: role of vitamin D. Am. J. Physiol., 239 (Gastrointest. Liver Physiol. (2): G473 (1980).

18. Hargis, G. K., Bowser, E. N., Henderson. W. J., and Williams, G. A.: Radioim munoassay of rat parathyroid hormone in serum and tissue extracts. Endocrinology, 94: 1644 (1974).

19. Haussler. M. R.: Vitamin D: mode of action and biomedical applications. Nutr. Rev.. 32: 257 (1974)

20. Henning. S. J. and Kretchmer, N.: Development of intestinal function in animals. Enzyme, 15: 3 (1973)

21. Keen, C. L., Lonnerdal, B., Clegg, M., and Hurley, L.: Developmental changes in composition of rat milk: trace elements, minerals, proteins, carbohydrate and fat. J. Nutr. 111: 226 (1981).

22. Lowry, O. H., Rosebrough. N. J., Farr. A. L., and Randall, R. J.: Protein measurement with the Folin Phenol reagent. J. Biol. Chem., 193: 265 (1959).

23. Luckey, T. D., Menele, T. J., and Pleasants, J.: The physical and chemical characterization of rat's milk. J. Nutr., 54: 345 (1955).

24. Mancini. G.. Carbonara. H. O.. and Heremans, J. F.: Immunochemical quantitation of antigens by single radial immunodiffusion. Immunochemistry, 2: 235 (1965).

25. Marche, P., Pradelles, P.. Gros, C., and Thomasset, M.: Radioimmunoassay for a vitamin-D dependent calcium-binding protein in rat duodenal mucosa. Biochem. Biophys. Res. Commun., 76: 1020 (1977).

26. Miller, D. L.: Rat small intestine: development. composition and effects of perfusion. Am. J. Dig. Dis., 16: 247 (1971).

27. Ouchterlony, P. and Nilsson. L. A.: Immunodiffusion and immunoelectrophoresis. In: D. M. Weir. Ed.: Handbook of Experimental Immunology. pp. 19.119.39 (Blackwell Scientific Publications, London, England, 1973).

28. Schachter, D., Dowdle. E. B., and Schenker, H.: Accumulation of Ca ${ }^{4 ! 1}$ by slices of the small intestine. Am. J. Physiol., 198(2): 275 (1960).

29. Tsai. H. C. and Norman. A. W.: Studies on the mode of action of calciferol V 1 : effect of 1.25-dihydroxy-vitamin D3 on RNA synthesis in the intestinal mucosa. Biochem. Biophys. Res. Commun., 54: 622 (1973).

30. Urban, E. and Schedl, H. P.: Comparison of in vivo and in vitro effects of vitamin $\mathrm{D}$ in calcium transport in the rat. Amer. J. Physiol., 217: 126 (1969).

31. Wasserman, R. H. and Taylor, A. N.: Vitamin D-dependent calcium-binding protein. Response to some physiological and nutritional variables. J. Biol. Chem., 243: 3987 (1968).

32. Younoszai, M. K. and Ghishan, F. K.: In vivo intestinal calcium transport in infant rats: normal and growth retarded. J. Nutr.. 109: 573 (1979).

33. Zerwekh, J. E., Lindell, T. J., and Haussler, M. R.: Increased chromatin template activity. Influence of 1 $\alpha, 25$-dihydroxy-vitamin D3 and hormonereceptor complexes. J. Biol. Chem., 251: 2338 (1976).

34. Presented in part to the combined meeting of the Southern Section of the American Federation for Clinical Research, the Southern Society for Pediatric Research, and the Southern Society for Clinical Investigation. New Orleans, Louisiana, January 18,1981 and to the combined meeting of the Society for Pediatric Research and the American Pediatric Society, San Francisco, California, April 28, 1981.

35. Requests for reprints should be addressed to: Dr. W. A. Gleason, Jr., Division of Gastroenterology and Nutrition. Department of Pediatrics. University of Texas Health Science Center, 7703 Floyd Curl Drive, San Antonio, Texas 78284.

36. This research was supported in part by the University of Texas Health Science Center, Institutional Research Grant \#OR-07.

37. Received for publication July 6. 1981.

38. Accepted for publication February 8, 1982 